\title{
ARTICLES
}

\section{Expression of Interleukin-7 and Its Receptor in Thyroid Lymphoma}

\author{
Tetsuya Takakuwa, Shintaro Nomura, Fumio Matsuzuka, Hiromasa Inoue, and \\ Katsuyuki Aozasa
}

Department of Pathology (TT, SN, HI, KA), Osaka University Medical School, Suita, and the Section of Surgery (FM), Kuma Hospital, Kobe, Japan

\begin{abstract}
SUMMARY: Patho-epidemiological studies have shown that thyroid lymphomas (TL) develop in thyroids affected by chronic lymphocytic thyroiditis (CLTH). Cytokines produced in CLTH might play a pivotal role for lymphomagenesis, because previous reports indicate an important role of cytokines in lymphomagenesis. We examined the expression of interleukin-7 (IL-7), a pleiotropic cytokine that acts mainly on cells of the hematolymphoid system, and IL-7 receptor (IL-7R) in both TL and CLTH by RT-PCR. IL-7-specific transcripts were detected more frequently in TL than in CLTH lesions $(p<0.01)$. IL-7 expression was higher in TL than in CLTH. IL-7R and the common gamma chain were expressed in all but one TL and in all CLTH lesions, in similar levels. We established the sensitive in situ hybridization (ISH) method for detection of IL-7. ISH for IL-7 revealed cytoplasmic signals among cells in the germinal center and mantle zone of lymphoid follicles and interfollicular areas in the TL and CLTH lesions. In the lymphomatous areas of TL, similar numbers of scattered large and small lymphoid cells expressing IL-7 were found. The number of IL-7-expressing cells counted in 10 fields in TL (119.4 \pm 10.6 cells) was significantly higher than found in CLTH lesions $(43.1 \pm 4.6)(p<0.001)$. These findings suggest a pathogenetic role for IL-7 in the development of TL. ISH showed that the germinal center cells, interfollicular cells, and lymphoma cells expressed IL-7R, but mantle zone cells did not. Because lymphoid cells in lymphoid follicles and the interfollicular area formed in CLTH expressed IL-7, TL cells might proliferate via their own IL-7 and IL-7R, and via IL-7 from reactive lymphoid cells. (Lab Invest 2000, 80:1483-1490).
\end{abstract}

$T$ hyroid lymphoma (TL) is a minor constituent of non-Hodgkin's lymphoma, accounting for $2.5 \%$ of all cases of extranodal lymphomas in the series of Freeman and associates from North America (Freeman et al, 1972) and for $2.2 \%$ of the cases in our series from Japan (Aozasa et al, 1985). TL attracted the attention of investigators because of its putative origin from active lymphoid cells in autoimmune lymphocytic thyroiditis, ie, Hashimoto's thyroiditis or chronic lymphocytic thyroiditis (CLTH) (Volpe, 1975). Follow-up studies confirmed an important role of CLTH in the development of TL (Kato et al, 1985). Based on the patho-epidemiological studies on the malignant lymphomas, we proposed the concept of a malignant lymphoma, exclusively B-cell type, developing in chronic inflammation (luchi et al, 1989). TL could be included in this category.

Received February 23, 2000.

Supported by a grant from Vehicle Racing Commemorative Foundation and grants from the Ministry of Education, Science and Culture, Japan (09670184, 09770148, 10042005, 10151225, 11470353, 11670212, 11680546).

Address reprint requests to: Dr. Katsuyuki Aozasa, Department of Pathology (C3), Osaka University Medical School, 2-2 Yamada-oka, Suita, Osaka 5650871, Japan.Fax: 81 668793713;E-mail:aozasa@molpath.med.osaka-u.ac.jp
Cytokines that are produced from lymphoma cells and/or reactive cells surrounding tumor cells might provide a growth advantage for lymphoma cells. Because TL is a lymphoma that develops in chronic inflammation, some cytokines might play a role in lymphomagenesis. Therefore, we first examined a difference in cytokine profiles between TL and CLTH (unpublished data). The results showed that, except for interleukin-7 (IL-7), there seemed to be no prominent differences between TL and CLTH in profiles of cytokines examined, which included interferon $\gamma$ (IFN $\gamma$ ), IL-2, IL-6, and IL-10. IL-7 is mainly produced by bone marrow stromal cells and initially found to be a growth factor for pre-B cells (Appasamy, 1995). Subsequent studies revealed that this cytokine also has major effects on both immature and mature $T$ cells, cytotoxic T cells and natural killer cells (Naume and Espevik, 1991). At higher concentrations, IL-7 induces the secretion of IL- $1 \alpha$ and $\beta, \mathrm{IL}-6$, and tumor necrosis factor by monocytes (Alderson et al, 1991). IL-7 receptor (IL-7R) is expressed in developing T cells and developing $B$ cells together with bone-marrowderived macrophages (Appasamy, 1995).

IL-7 is a growth factor for acute lymphoblastic leukemia of early B-cell or T-cell phenotype (Eder et al, 1992) and Sezary cells (Dalloul et al, 1992). Additionally, IL-7 is expressed in a human B-cell line (Benjamin 
et al, 1994), a subset of tumor cells of B-cell chronic lymphocytic leukemia (Frishman et al, 1993) and classical Hodgkin's disease (Foss et al, 1995). On the other hand, implantation of various tumor cell lines transfected with the mouse IL-7 gene into mice consistently resulted in strong inflammatory responses, which were composed of a variety of cell types (Aoki et al, 1992; McBride et al, 1992). These data, together with the finding that IL-7-transgenic mice develop a progressive cutaneous lymphoproliferative disorder and generalized lymphoproliferation that progress to malignancy, point to an important role of this cytokine in lymphomagenesis (Rich et al, 1993).

In the present study, we examined the expression of IL-7 and IL-7R in TL and CLTH lesions by RT-PCR. Additionally, we established the original method of in situ hybridization (ISH) to identify IL-7- and IL-7Rexpressing cells, and applied this method to the lesional tissues.

\section{Results}

\section{RT-PCR Analysis}

IL-7-specific transcripts were detected in 6 of 10 CLTH cases and in all of the TL cases (Fig. 1), but not in any of the control thyroid tissues. Detection frequency was significantly higher in TL than in CLTH, as determined by the chi-square test $(p<0.01)$. Expression levels were higher in TL cases, especially in diffuse large cell lymphomas, compared with CLTH cases. Expression of IL-7R and the common cytokine receptor $\gamma$-chain, which associates with IL-7R and IL-2, IL-4, and IL-13 receptors, was examined. IL-7R and $\gamma$ common chain were expressed in all but one TL, and in all of the CLTH and control cases. There were no prominent differences in expression levels of IL-7R and common cytokine receptor $\gamma$-chain between CLTH, control, and TL cases. Expression levels might

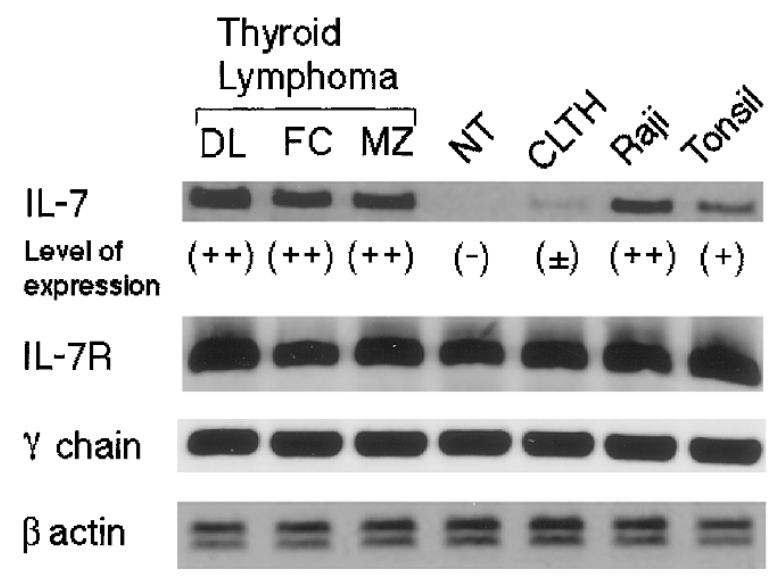

Figure 1.

RT-PCR analysis was performed using specific primers for interleukin-7 (IL-7) and IL-7 receptor (IL-7R), with $\beta$-actin primers as a control. Results in the representative cases with specific histologic categories are shown. DL, diffuse large lymphoma; FC, follicular center lymphoma; MZ, marginal zone lymphoma; NT, normal thyroid tissue as control; CLTH, chronic lymphocytic thyroiditis. Raji, Raji cell line as control; Tonsil, tonsil tissue as control. be affected by the total number of lymphoid cells in the thyroid lesions, ie, CLTH tissues more frequently contained residual thyroid tissues or fibrotic tissues devoid of lymphoid cells. However, the finding that IL-7R expression levels in CLTH were similar to levels in TL cases combined with the finding that the number of IL-7-expressing lymphoid cells defined by the ISH method was larger in TL than in CLTH confirms a higher expression of IL-7 in TL than in CLTH.

\section{ISH for IL-7 and IL-7R and Immunohistochemistry for IL-7R}

Cells expressing IL-7 and IL-7R mRNA were identified using ISH. Intracytoplasmic expression of IL-7 was found among cells in the germinal centers and mantle zone of lymphoid follicles, in the interfollicular areas in the TL and CLTH lesions, and in the tonsil (Fig. 2). IL-7-expressing cells in CLTH and TL had roundshaped cytoplasms (Fig. 3, inset), indicating that these are lymphoid cells. In TL, roughly equal numbers of large and small lymphoid cells expressed IL-7. The number of IL-7-expressing cells was significantly larger in TL $(119.4 \pm 10.6)$ than in CLTH $(43.1 \pm 4.6)(p$ $<0.001)$. Vascular endothelial cells and squamous epithelial cells of tonsils also expressed IL-7. ISH showed that the germinal center cells, interfollicular reactive cells, and lymphoma cells, but not the mantle zone cells of lymphoid follicles expressed IL-7R (Fig. 3). Thyroid follicular epithelium did not express IL-7R. Therefore, transcripts of IL-7R in control thyroid tissues from thyroid cancer patients might be derived from infiltrating inflammatory cells near the cancer. The distribution pattern of cells expressing IL-7R protein determined by immunohistochemistry was same as the IL-7R mRNA pattern.

Recently, it was reported that follicular dendritic cells (FDC) and vascular endothelial cells expressed IL-7 (Kroncke et al, 1996). Therefore, we examined the immunoreactivity of CLTH and TL tissues for anti-FDC antibodies, CNA 42 and CD21. A typical immunoreactive pattern of the FDC network was observed in the germinal center scattered in CLTH and TL lesions and vascular endothelial cells, and lymphoma cells themselves were also occasionally immunoreactive (Fig. 4). As shown in Figures 2 and 3, IL-7-expressing cells were round-shaped with sharp cell borders, excluding the possibility that these cells might be FDC.

\section{Discussion}

Cytokines might play a pivotal role in lymphomagenesis. Roles for IL-2 for tumor growth of follicular lymphoma or some peripheral T-cell lymphoma (Appasamy, 1995), IL-6 for B-cell or T-cell lymphoma (Yee et al, 1989), or IL-10 for B-cell lymphoma (Moore et al, 1993) have been suggested. Cytokines produced from lymphoma cells and/or reactive inflammatory cells intermingling with tumor cells could provide growth advantages for lymphoma in either an autocrine or paracrine fashion (Tosato et al, 1993). Recently, we reported growth-promotional effects of IL-6 and IL-10 

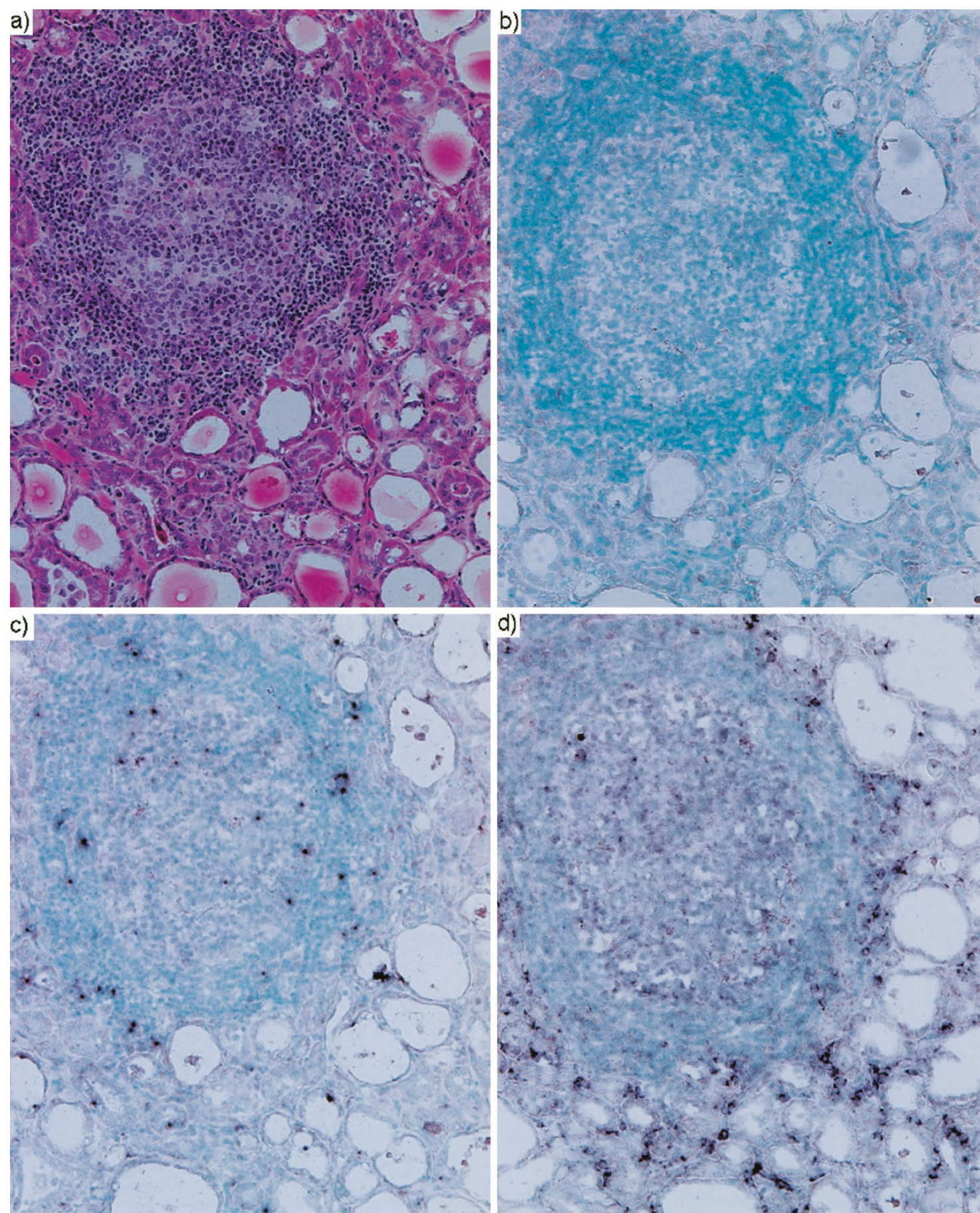

\section{Figure 2.}

In situ hybridization (ISH) demonstrating the distribution of IL-7/IL-7R mRNA-expressing cells in chronic lymphocytic thyroiditis (CLTH). Serial sections from a CLTH case of hematoxylin and eosin staining (a), after colorimetric detection of hybridized digoxigenin-labeled human IL-7R sense (negative control) (b), IL-7 antisense $(c)$, and IL-7R antisense $(d)$. Original magnification, $\times 50$.

on the pyothorax-associated lymphoma, a malignant lymphoma that can develop in chronic inflammation (Kanno et al, 1996; 1997). Therefore, we compared the profiles of several cytokines by semi-quantitative RTPCR among CLTH and TL lesions. The results showed that the expression pattern of only IL-7 was different between these lesions (unpublished data). Although these findings do not deny the possible contribution of cytokines other than IL-7 for thyroid lymphomagen- esis, we concentrated on the investigation of IL-7 in this study.

The human IL-7 gene is located on chromosome 8q12-13, and encodes the IL-7 protein (molecular weight $2.5 \times 10^{3}$ d) (Appasamy, 1995). Previous studies showed that bone marrow and thymic stromal cells and keratinocytes produce IL-7 protein. A number of tumor cells and cell lines, including B-cell chronic lymphocytic leukemia cells, EBV-transformed B-cell 

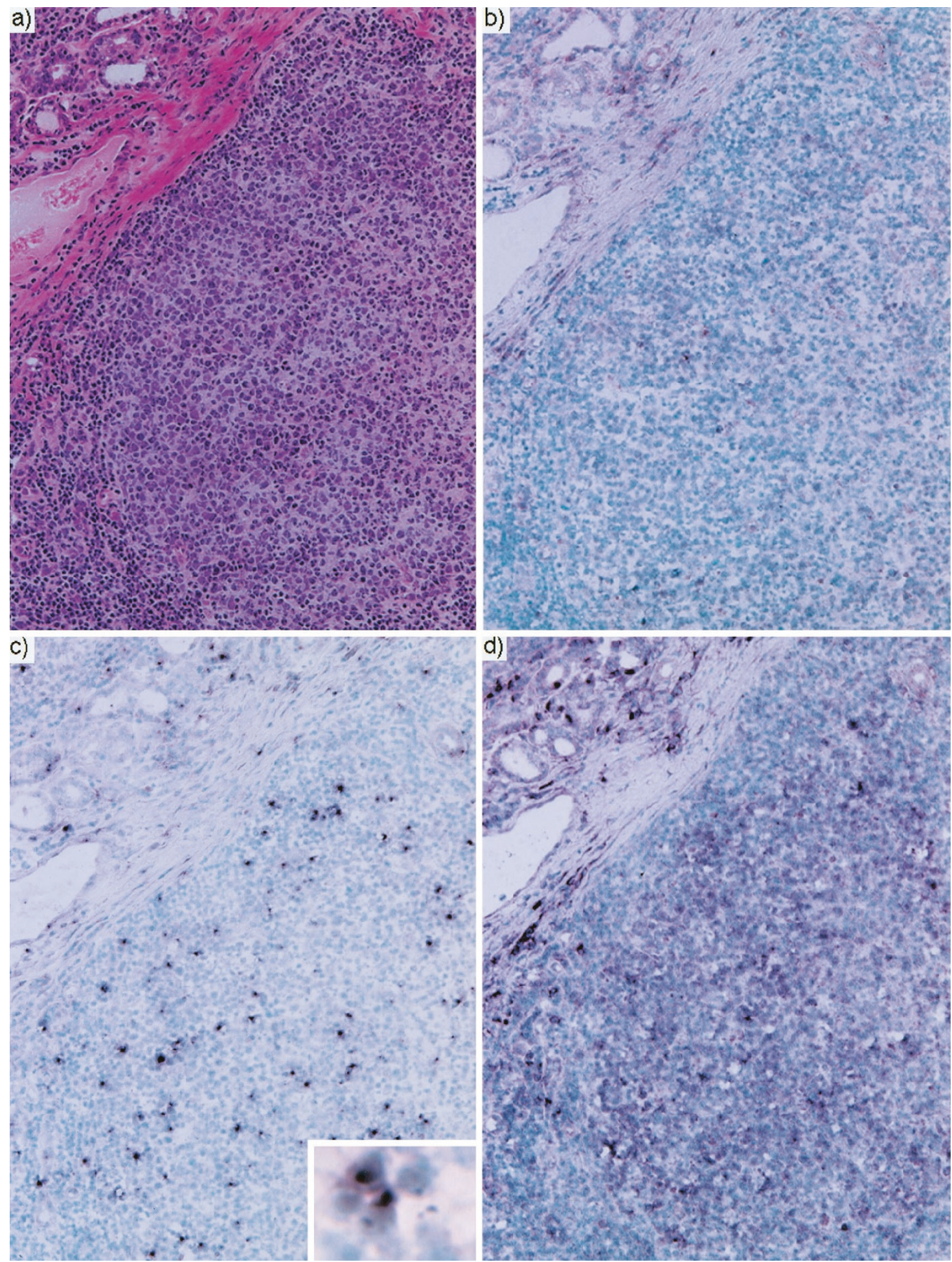

Figure 3.

ISH demonstrating the distribution of IL-7/IL-7R mRNA-expressing cells in thyroid lymphoma tissue. Serial sections from a follicular center lymphoma of hematoxylin and eosin staining (a), after colorimetric detection of hybridized digoxigenin-labeled human IL-7R sense (negative control) (b), IL-7 antisense (c), and IL-7R antisense (d). Original magnification, $\times 50$. Inset: higher magnification of IL-7-expressing cells. Original magnification, $\times 300$. Note that both IL-7-and IL-7R-expressing cells are scattered in the lymphomatous area, but the distribution of IL-7-expressing cells is not identical with IL-7R-expressing cells.

lines, and Burkitt's lymphoma cells also produce IL-7 (Benjamin et al, 1994; Frishman et al, 1993). These results were principally based on the biochemical analyses, because in situ detection of IL-7 has been difficult. Therefore, precise information on the IL-7- expressing cells in lymphoid tissues was limited. By using isotopic ISH with a ${ }^{35} \mathrm{~S}$-labeled RNA probe specific for IL-7 and prolonged exposure times (up to 10 weeks), Foss et al reported the expression of IL-7 transcripts in Hodgkin and Reed-Sternberg cells but 

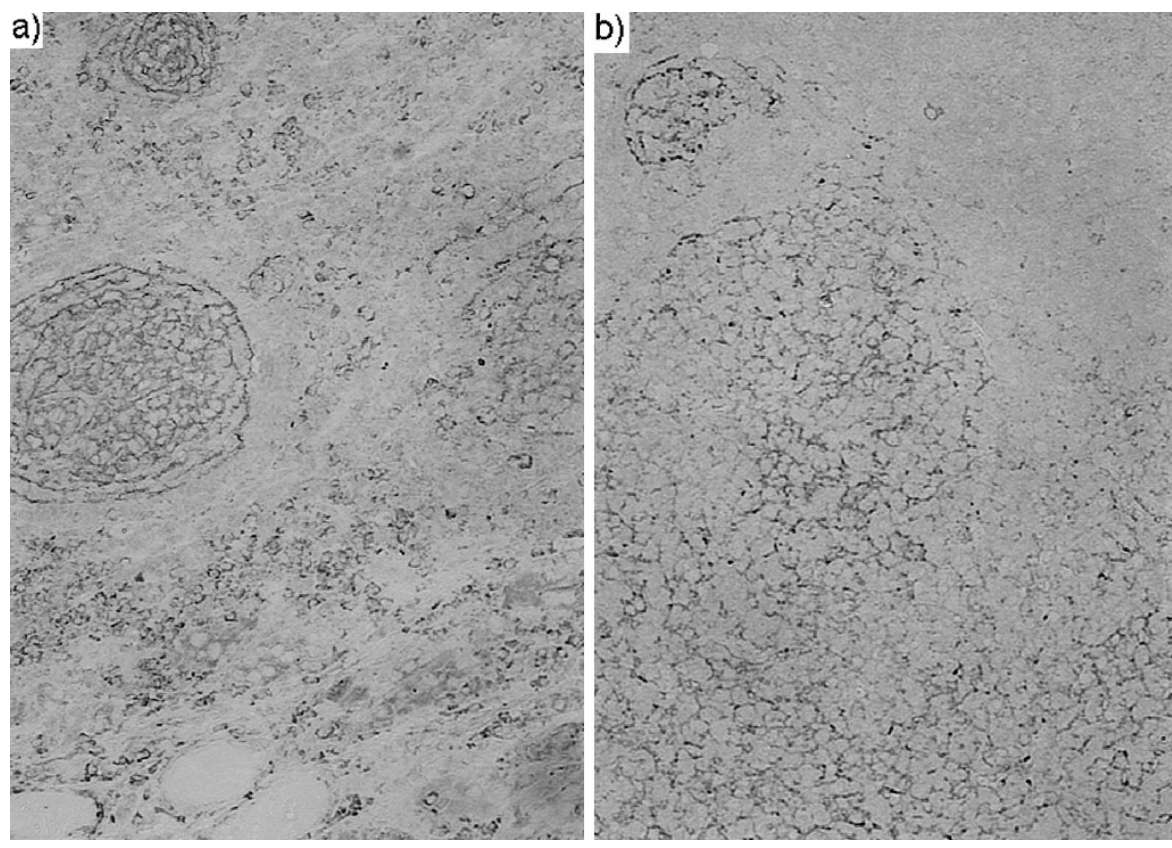

Figure 4.

A typical pattern of the follicular dendritic cell (FDC) network visualized with the FDC-restricted antibody CNA 42 in CLTH tissue (a) and thyroid lymphoma (TL) tissue (b).

rarely in the reactive cells in classical Hodgkin's disease (Foss et al, 1995). Lymphoblastic lymphoma cells were occasionally labeled, but no B-cell chronic lymphocytic leukemia cells, FDC, or vascular endothelial cells were labeled. Foss et al's method could not show positive signals in the endothelial cells, thus seems less sensitive than our ISH method. Additionally, precise identification of labeled cells was difficult in ISH with isotopic labeling.

We established an ISH method using digoxigenin11-UTP-labeled single strand RNA probes that gave higher resolution and detection results for IL-7- and IL-7R-expressing cells. This method produced clear and reproducible IL-7 and IL-7R signals in lymphoid tissues. In the reactive lymphoid tissues in the thyroid, which are formed in CLTH, IL-7-expressing cells were found in the germinal center, mantle zone, and interfollicular area. Epithelial cells of thyroid follicles did not express IL-7, in agreement with the RT-PCR results, which showed that control thyroid tissue did not express IL-7. IL-7R was expressed among cells in the germinal center and interfollicular area but not in the mantle zone. This is the first report of the in situ distribution of IL-7-expressing cells in lymphoid tissues.

The ISH method clearly demonstrated that lymphoma cells per se expressed IL-7 and IL-7R. The distribution of IL-7-expressing cells was not identical with IL-7R-expressing cells on the serially cut sections. Because lymphoid cells expressed IL-7 in lymphoid follicles and the interfollicular area formed in CLTH, TL cells might proliferate in a paracrine or autocrine manner via their own IL-7 and IL-7R, and via IL-7 from reactive lymphoid cells. The semiquantitative RT-PCR method showed that the expres- sion levels of IL-7 in TL were higher than the levels in CLTH. This may be a result of the significantly increased number of IL-7-expressing cells in TL, including the large lymphoma cells and small lymphoid cells, compared with CLTH, revealed by ISH method. These findings suggest a pathogenetic role of IL-7 in the development of TL.

RT-PCR analysis showed both IL-7 and IL-7R transcripts in the nodal B-cell lymphomas but only IL-7R transcripts in the peripheral T-cell lymphomas (unpublished data). These findings suggested a positive role of IL-7 and IL-7R in B-cell lymphomagenesis, which was not restricted to B-cell lymphomas developing in chronic inflammation. Further study to examine growth promotional effects of IL-7 on neoplastic B-cells and to examine whether binding of IL-7 with its receptor induces signal transduction is needed.

\section{Materials and Methods}

\section{Cases}

Thyroid specimens were collected from 21 patients with TL, 10 patients with CLTH, and 4 patients with thyroid carcinoma. Patients with thyroid masses were admitted to Kuma Hospital (Kobe City, Japan) between 1995 and 1998. Microsatellite instability and $\mathrm{k}$-ras and p53 mutations in some of these TL and CLTH cases were previously reported. All but five TL patients were male. The age ranges of the patients at the time of admission were 47 to 85 (median 65) years with TL, 52 to 75 (median 66) years with CLTH, and 39 to 69 (median 50) years with thyroid carcinoma. All patients underwent surgery including total thyroidectomy, partial thyroidectomy, or open biopsy. The 
histologic specimens were fixed in 10\% formalin and routinely processed for paraffin embedding. Samples in all cases were snap frozen with or without OCT compound at $-150^{\circ} \mathrm{C}$, and stored at $-80^{\circ} \mathrm{C}$ until use. Criteria for the diagnosis of CLTH included increased consistency of the thyroid gland, occasional hypothyroidism, high level of $\mathrm{TSH}$, low ${ }^{123}$ I-uptake, and the presence of antimicrosomal and/or antithyroglobulin antibodies in the serum. Histologic findings of the CLTH included lymphocytic infiltration (usually forming lymphoid follicles with germinal centers), varying degrees of fibrosis, and oxyphilic change or squamous metaplasia of epithelial cells of the thyroid follicles. TL were classified according to the revised European-American Classification for Lymphoid Neoplasms (Harris et al, 1994). In the majority of cases with TL, the presence of lymphoid follicles with germinal center could be confirmed, indicating preexisting CLTH.

Tonsils from four patients with chronic tonsillitis were collected, and used as controls for ISH.

\section{Isolation of RNA and cDNA Synthesis}

Tissue samples from TL and CLTH were homogenized and total RNA was extracted in the presence of Trizol reagent (GIBCO BRL, Grand Island, New York). Total RNA from non-involved thyroid tissue of thyroid cancer patients was used as a control. Five micrograms of total RNA was reverse-transcribed using a first-strand cDNA synthesis kit (Amersham Pharmacia Biotech, Buckinghamshire, United Kingdom).

\section{Normalization of Sample $\beta$-Actin Content by Competitive PCR}

To compare cytokine mRNA expression in the different tissue samples accurately, it is essential to use equivalent amounts of substrate cDNA. For comparison of cytokine mRNA levels among multiple thyroid specimens, we normalized all samples for $\beta$-actin cDNA content by competitive PCR. We constructed a competitor using a competitive DNA construction kit (Takara, Kusatsu, Japan). Briefly, the competitor was constructed by PCR of a $\lambda$ DNA using $\beta$-actin-com- petitor primers that contained $\beta$-actin sequences at the $5^{\prime}$ end (Table 1). The competitor product DNA, identified by its size of $339 \mathrm{bp}$, was purified. One set of $\beta$-actin primers amplified the $\beta$-actin cDNA in both samples and competitor. The PCR products of both target and competitor were subjected to agarose gel electrophoresis. The competitor DNA generated a longer PCR product than the target cDNA. To quantify $\beta$-actin cDNA levels, serial 5 -fold dilutions of known amounts of the competitor cDNA were added to $1 \mu \mathrm{l}$ of CDNA and amplified by PCR, using primers specific for $\beta$-actin. The concentration of substrate sample cDNA was calculated from the concentration of competitor DNA that generated equal amounts of competitor and sample products. To normalize the sample cDNA concentrations, all samples were diluted to a concentration of $10^{8}$ copies/ $\mu$ l of $\beta$-actin.

\section{Gene Expression of Cytokines and Receptors}

The cDNA was then amplified by PCR using the primers specific for IL-7 and its receptor. The primer sequences, amplification product sizes, annealing temperatures, and cycles of amplification are shown in Table 1. Fifteen microliters of reaction mixture containing $1 \mu \mathrm{l}$ of cDNA, $0.2 \mu \mathrm{M}$ of the proper pair of each primer, $0.25 \mathrm{~mm}$ of each deoxynucleotide triphosphate, 1x PCR buffer, and 0.6 U of Ampli Taq Gold DNA polymerase (Perkin-Elmer Cetus, Norwalk, Connecticut) were amplified. PCR products were electrophoresed in a $2.0 \%$ agarose gel, and visualized by staining with ethidium bromide.

\section{ISH for Detection of IL-7 and IL-7R mRNA}

Digoxigenin-11-UTP-labeled single strand RNA probes were prepared using the DIG RNA labeling Kit (Boehringer-Mannheim Biochemica, Mannheim, Germany) according to the manufacturer's instructions. For generation of antisense and sense probes, fragments of human IL-7 and IL-7R cDNA were obtained by RT-PCR as described above in "Isolation of RNA and cDNA Synthesis." These PCR fragments were subcloned into Bluescript I pKS.

Table 1. Primer Sets for RT-PCR

\begin{tabular}{|c|c|c|c|c|c|}
\hline & & Sequence forward/reverse & $\begin{array}{c}\text { cDNA } \\
\text { (bp) }\end{array}$ & $\begin{array}{c}\mathrm{Ta} \\
\left({ }^{\circ} \mathrm{C}\right)\end{array}$ & Cycles \\
\hline \multirow[t]{2}{*}{ IL-7 } & Up & 5'TTTTATTCCGTGCTGCTCGC3' & 429 & 66 & 37 \\
\hline & Down & 5'GCCCTAATCCGTTTTGACCA3' & & & \\
\hline \multirow{2}{*}{ IL-7R } & Up & 5'GAAGGTTGGAGAAAAGAGTC3' & 418 & 52 & 30 \\
\hline & Down & 5'CAAAATGCTGATGGTTAGTAAG3' & & & \\
\hline \multirow[t]{2}{*}{$\gamma$-chain } & Up & 5'ACGGGAACCCAGGAGACAGG3' & 275 & 52 & 30 \\
\hline & Down & 5'AGCGGCTCCGAACACGAAAC3' & & & \\
\hline \multirow{2}{*}{$\beta$-actin } & Up & 5'CTTCCTTCCTGGGCATGGAG3' & 315 & 66 & 25 \\
\hline & Down & 5'TGGAGGGGCCGGACTCGTCA3' & & & \\
\hline \multirow[t]{2}{*}{$\beta$-actin competitor } & Up & 5'CTTCCTTCCTGGGCATGGAG-TACGGTCATCATCTGACAC3' & 339 & 66 & 25 \\
\hline & Down & 5'TGGAGGGGCCGGACTCGTCA-CGCCATCCTGGGAAGACTCC3' & & & \\
\hline
\end{tabular}

Ta, annealing temperature; IL-7, interleukin-7; IL-7R, interleukin-7 receptor. 
Table 2. IL-7 mRNA Expression in Thyroid Tissues

\begin{tabular}{|c|c|c|c|c|c|}
\hline \multirow[b]{2}{*}{ Histology } & \multirow{2}{*}{$\begin{array}{l}\text { No. of } \\
\text { cases }\end{array}$} & \multicolumn{4}{|c|}{ Level of expression } \\
\hline & & ++ & + & \pm & - \\
\hline Chronic Iymphocytic thyroiditis & 10 & 1 & 1 & 4 & 4 \\
\hline Thyroid lymphoma & 21 & 7 & 14 & 0 & 0 \\
\hline diffuse large B-cell lymphoma & 10 & 5 & 5 & 0 & 0 \\
\hline low-grade MALToma ${ }^{a}$ & 7 & 1 & 6 & 0 & 0 \\
\hline follicle center cell lymphoma & 4 & 1 & 3 & 0 & 0 \\
\hline Control & 4 & 0 & 0 & 0 & 4 \\
\hline
\end{tabular}

${ }^{a}$ Marginal zone B-cell lymphoma and lymphoplasmacytic lymphoma.

Hybridization was carried out according to the BMY visual (videotape) and original protocol (BoehringerMannheim Yamanouchi, Tokyo, Japan) with minor modification (Hirota et al, 1992). Briefly, $6 \mu \mathrm{m}$-thick frozen sections were fixed in $4 \%$ paraformaldehyde and incubated with $1.5 \mu \mathrm{g} / \mathrm{ml}$ of proteinase $\mathrm{K}$ (Boehringer-Mannheim Biochemica) in $10 \mathrm{~mm}$ Tris- $\mathrm{HCl}$ (pH 8.0) and $1 \mathrm{~mm}$ EDTA for 1 to 8 minutes at $37^{\circ} \mathrm{C}$. Sections were re-fixed with $4 \%$ paraformaldehyde for 10 minutes, treated with $0.2 \mathrm{~N} \mathrm{HCl}$ for 10 minutes, equilibrated with $0.1 \mathrm{M}$ triethanolamine- $\mathrm{HCl}$ buffer $(\mathrm{pH}$ 8.0) for 2 minutes, and acetylated by incubating with freshly prepared $0.25 \%$ acetic anhydride in $0.1 \mathrm{M}$ triethanolamine- $\mathrm{HCl}$ buffer $(\mathrm{pH} 8.0)$ for 10 minutes. The sections were then incubated at $50^{\circ} \mathrm{C}$ for 16 hours with the hybridization solution containing 50\% deionized formamide, $10 \%$ dextran sulfate, 1x Denhardt's solution, $600 \mathrm{~mm} \mathrm{NaCl}, 0.25 \%$ SDS, $250 \mu \mathrm{g} / \mathrm{ml}$ of Escherichia coli tRNA (proteinase treated), $10 \mathrm{~mm}$ DTT (dithiothreitol), and 0.1 to $2.0 \mu \mathrm{g} / \mathrm{ml}$ of digoxigenin-UTP-labeled RNA probe. Then the sections were washed with $50 \%$ formamide in $2 x$ SSC for 30 minutes at $50^{\circ} \mathrm{C}$ to remove excess probe. RNase $\mathrm{A}$ treatment $(10 \mu \mathrm{g} / \mathrm{ml})$ was carried out at $37^{\circ} \mathrm{C}$ in TNE $(10 \mathrm{~mm}$ Tris- $\mathrm{HCl}, 1 \mathrm{~mm}$ EDTA, $500 \mathrm{~mm} \mathrm{NaCl}$ ) buffer for 30 minutes. The slides were incubated with 2x SSC and $0.2 x$ SSC for 15 minutes twice at $50^{\circ} \mathrm{C}$. Immunodetection of hybridized probe was carried out according to the DIG-detection original protocol (BoehringerMannheim Biochemica). The number of IL-7-expressing cells were counted in 10 randomly selected highpower fields, areas occupied by lymphoid cells were selected for counting. The differences in IL-7-expressing cells between CLTH and TL were estimated by Student's $t$ test.

\section{Immunohistochemistry}

Immunohistochemistry on the paraffin sections was performed using the avidin-biotin-peroxidase complex (ABC) method. Monoclonal primary antibodies used included L26 (CD20), CD3, UCHL-1 (CD45RO), CD21, FDC (CNA 42) (DAKO, Glostrup, Denmark), MB-1, and MT-1 (CD43) (BioScience Emmenbrucke, Switzerland). For detection of the IL-7R protein, a rabbit anti-human IL-7R antibody (clone M29, IgG2b; Genzyme Corporation, Cambridge, Massachusetts) or an isotype-matched control antibody (DAKO) was used.
Lymphoma cells in all cases showed a B-cell phe-

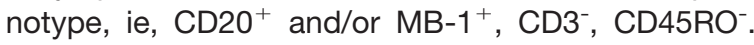
Then, the TL of this series were classified as diffuse large B-cell lymphoma (DLBL) in 10 cases, follicle center lymphoma in 4 cases, marginal zone B-cell lymphoma of extranodal type in 6 cases, and lymphoplasmacytic lymphoma in 1 case.

\section{References}

Alderson MR, Tough TW, Ziegler SF, and Grabstein $\mathrm{KH}$ (1991). Interleukin 7 induces cytokine secretion and tumoricidal activity by human peripheral blood monocytes. J Exp Med 173:923-930.

Aoki T, Tashiro K, Miyatake S, Kinashi T, Nakano T, Oda Y, Kikuchi H, and Honjo T (1992). Expression of murine interleukin 7 in a murine glioma cell line results in reduced tumorigenicity in vivo. Proc Natl Acad Sci U. S. A. 89:3850-3854.

Aozasa K, Tsujimoto M, Sakurai M, Honda M, Yamashita K, Hanada M, and Sugimoto A (1985). Non-Hodgkin's lymphomas in Osaka, Japan. Eur J Cancer Clin Oncol 21:487-492.

Appasamy PM (1995). Interleukin-7 and lymphopoiesis: Biological and clinical implications. Cancer Treat Res 80:235-260.

Benjamin D, Sharma V, Knobloch TJ, Armitage RJ, Dayton MA, and Goodwin RG (1994). Human B cell lines constitutively secrete IL-7 and express IL-7 receptors. J Immunol 152:4749-4757.

Dalloul A, Laroche L, Bagot M, Mossalayi MD, Fourcade C, Thacker DJ, Hogge DE, Merle BH, Debre P, and Schmitt C (1992). Interleukin-7 is a growth factor for Sezary lymphoma cells. J Clin Invest 90:1054-1060.

Eder M, Ottmann OG, Hansen HT, Bartram CR, Falk S, Gillis S, Hoelzer D, and Ganser A (1992). In vitro culture of common acute lymphoblastic leukemia blasts: Effects of interleukin-3, interleukin-7, and accessory cells. Blood 79:3274-3284.

Foss HD, Hummel M, Gottstein S, Ziemann K, Falini B, Herbst $H$, and Stein H (1995). Frequent expression of IL-7 gene transcripts in tumor cells of classical Hodgkin's disease. Am J Pathol 146:33-39.

Freeman C, Berg JW, and Cutler SJ (1972). Occurrence and prognosis of extranodal lymphomas. Cancer 29:252-260.

Frishman J, Long B, Knospe W, Gregory S, and Plate J (1993). Genes for interleukin 7 are transcribed in leukemic cell subsets of individuals with chronic lymphocytic leukemia. $J$ Exp Med 177:955-964. 
Harris NL, Jaffe ES, Stein H, Banks PM, Chan JK, Cleary ML, Delsol G, De WPC, Falini B, and Gatter KC (1994). A revised European-American classification of lymphoid neoplasms: A proposal from the International Lymphoma Study Group. Blood 84:1361-1392.

Hirota S, Ito A, Morii E, Wanaka A, Tohyama M, Kitamura Y, and Nomura S (1992). Localization of mRNA for c-kit receptor and its ligand in the brain of adult rats: An analysis using in situ hybridization histochemistry. Brain Res Mol Brain Res 15:47-54.

Iuchi K, Aozasa K, Yamamoto S, Mori T, Tajima K, Minato K, Mukai K, Komatsu H, Tagaki T, Kobashi Y, Yamabe H, and Shimoyama M (1989). Non-Hodgkin's lymphoma of the pleural cavity developing from long-standing pyothorax. Summary of clinical and pathological findings in thirty-seven cases. Jpn J Clin Oncol 19:249-257.

Kanno H, Naka N, Yasunaga Y, luchi K, Yamauchi S, Hashimoto M, and Aozasa K (1997). Production of the immunosuppressive cytokine interleukin-10 by Epstein-Barr-virusexpressing pyothorax-associated lymphoma: Possible role in the development of overt lymphoma in immunocompetent hosts. Am J Pathol 150:349-357.

Kanno H, Yasunaga Y, luchi K, Yamauchi S, Tatekawa T, Sugiyama H, and Aozasa K (1996). Interleukin-6-mediated growth enhancement of cell lines derived from pyothoraxassociated lymphoma. Lab Invest 75:167-173.

Kato I, Tajima K, Suchi T, Aozasa K, Matsuzuka F, Kuma K, and Tominaga $S$ (1985). Chronic thyroiditis as a risk factor of B-cell lymphoma in the thyroid gland. Jpn J Cancer Res 76:1085-1090.
Kroncke R, Loppnow H, Flad HD, and Gerdes J (1996). Human follicular dendritic cells and vascular cells produce interleukin-7: A potential role for interleukin-7 in the germinal center reaction. Eur J Immunol 26:2541-2544.

McBride WH, Thacker JD, Comora S, Economou JS, Kelley D, Hogge D, Dubinett SM, and Dougherty GJ (1992). Genetic modification of a murine fibrosarcoma to produce interleukin 7 stimulates host cell infiltration and tumor immunity. Cancer Res 52:3931-3937.

Moore KW, O'Garra A, de Waal Malefyt R, Vieira P, and Mosmann TR (1993). Interleukin-10. Annu Rev Immunol 11: 165-190.

Naume B and Espevik T (1991). Effects of IL-7 and IL-2 on highly enriched $\mathrm{CD}^{+} 6^{+}$natural killer cells. A comparative study. J Immunol 147:2208-2214.

Rich BE, Campos TJ, Tepper RI, Moreadith RW, and Leder P (1993). Cutaneous lymphoproliferation and lymphomas in interleukin 7 transgenic mice. J Exp Med 177:305-316.

Tosato G, Jones K, Breinig MK, McWilliams HP, and McKnight JL (1993). Interleukin-6 production in posttransplant lymphoproliferative disease. J Clin Invest 91:2806-2814.

Volpe R (1975). Thyroiditis: Current views of pathogenesis. Med Clin North Am 59:1163-1175.

Yee C, Biondi A, Wang XH, Iscove NN, de Sousa J, Aarden LA, Wong GG, Clark SC, Messner HA, and Minden MD (1989). A possible autocrine role for interleukin-6 in two lymphoma cell lines. Blood 74:798-804. 